\title{
Sociolinguistic Aspects of the Speech Act of Greeting in Persian and English
}

\author{
Roozbeh MORADI \\ M.A. student of Linguistics, Payame Noor University (PNU), Tehran, Iran \\ Email: info@rmoradi.ir
}

\begin{abstract}
The present study investigates the sociolinguistic aspects of the speech act of greeting and its differences regarding expressive or productive forms of greeting in Persian and English. Contrastive studies of speech acts of different languages could help to overcome the gap that might happen in interpersonal communication among the speakers of various languages. The current paper focuses on the descriptive sociolinguistic analysis of the speech act of 'greeting' and the style of greetings in the mentioned languages. We have used different methods like questionnaire, observation, interview, introspection and statistical analysis to collect data. The materials, which were analyzed, involve Persian greetings that take place in real-life situations and English greetings recorded in audiovisual materials downloaded from the internet. The results show that social contexts have their influence on expressing the speech act of greeting in both Persian and English, and that each language has its own peculiarities and even some similarities with the other one. We have defined how greeting operates in our life.
\end{abstract}

Keywords: speech act of greeting, greeting forms, communicative competence, gender, generation, social status.

\section{Introduction}

The purpose of this study is to reveal the influence of generation, gender and social distance on the way we express the speech act of greeting, and to discover the most frequently used verbal and nonverbal forms of greeting in Persian and English. Research questions, which were carefully formulated while the research was done, are:

1. How do social distance, generation and gender influence the speech act discourse of greeting in Persian and English?

2. What kind of differences and similarities exist in the sociolinguistic dimensions of greeting forms in Persian and English?

3. How can the results of this research be useful in teaching English greeting forms to a group of Persian students?

This research leads to the investigation of whether greeting forms diversify depending on the relationship between discourses in English and Persian. Furthermore, we are going to use certain qualitative and quantitative research approaches to contrast these two languages, in order to reveal similarities and peculiarities in sociolinguistic aspects of the speech act of greeting in Persian and English. 


\section{Material Studied and Area Descriptions}

As a significant aspect of politeness, greetings have been studied in disciplines such as sociology, anthropology, sociolinguistics and discourse analysis, yet there has been no systematic investigation of their use across different languages from both pragmatic and sociolinguistic perspectives ( $\mathrm{Li}, 2010)$.

Sociolinguistics is one of the new branches in linguistics, which highlights that a language cannot be alive out of context. In addition, sociolinguistics states that a language changes according to the speaker who utilizes it, to the time and place he uses it in. The speaker discloses his life and identity in his speech besides his sociocultural, economic and geographical coordinates in time and space.

In fact, some scholars may highlight that since speech is unquestionably a social concept, to research it without any reference to society would be useless. Two basic cases substantiate this opinion. First, you cannot take the notion of language $\mathrm{X}$ for granted since this is a social notion by itself as far as it is defined in terms of a group of people who speak this language. Therefore, if you want to define English, you have to define it based on the group of people who speak it. Second, speech has social functions, both as a means of communication and as a way of identifying social groups (Tagliamonte, 2006).

The speech act is one of the closely connected concepts to sociolinguistics. The term speech act was proposed by Austin (1962), and was further developed by his student Searle (1969). The speech act theory analyzes the functions of statements in accordance with the behavior of speakers and listeners in conversation. Searle as one of the founders of this theory has classified speech acts into the following categories:

1. Commissive speech acts: those that influence the speaker into committing a particular action.

2. Declarative speech acts: those that declare the reality.

3. Directive speech acts: those that impel the listener to do a concrete operation.

4. Expressive speech acts: those that express the speaker's attitude and sensations towards the proposition.

5. Assertive speech acts: those that portray circumstances and commit the speaker to the truth of the expressed proposition.

According to Searle's categorization, greetings fall into the category of expressive speech acts (Searle, 1969). The speech act of greeting is a particularly appropriate speech act to investigate in a culture because it acts as a reflection through which we can find out what is valued in a particular culture. We cannot start our conversation without a greeting. Everyone can find himself trying to express pleasure each time when he meets a hearer. Consequently, "greeting" is one of the most repeated expressive speech acts in our life (Jibreen, 2010).

Nemani and Nasekh (2013) mentioned that what we speak and the way we do it can disclose how polite we are; moreover, the listener learns a lot of things about our knowledge, personality, and social status simply by listening to us rather than by considering how we walk, eat and dress. By the forms of greeting, which we use in conversation, one can reach a conclusion about our attitude to him, about our politeness and about the way we were brought up.

Goffman (1971) preferred to describe greeting acts as "access rituals:" composed of two patterns, passing greetings and engaging greetings. Rite is determined as a "conventionalized act through which an individual portrays his respect and regard for some object of ultimate value". The functions of the greeting patterns mentioned above are similar. Greetings also have other observable physical behavior. "A selection from a set of behavioral displays is 
involved". Moreover, "a verbal salutation is likely provided along with a term of address". Briefly, greetings consist of a number of related behaviors:

(1) "Salutation"/ verbal form.

(2) Term of address.

(3) Gestures and mimics.

(4) Social context.

Firth (1973) also referred to greeting act as rite with verbal and non-verbal forms. The first one can occur in one of the three following linguistic unit forms:

(1) In question forms ("How do you do?", "What's up?", "How are you?" and so on.)

(2) In interjection forms ("Hello", "Hi" and so on.)

(3) In affirmation forms ("Good morning", "Good day", "Good evening" and so on.)

The last one can be expressed by gestures and mimics, that is, body language. The study done by Duranti (1997) shows us that greeting forms have their correlation with the culture of the speaker. He is one of the scholars who underlined the speech act of greeting as the one which helps us discover more cultural, personal and historical information about the person who utters it or about the nation who uses those particular greeting forms instead of other speech acts. We can say that his works are the basic foundations of all research works concerning the speech act of greeting. Jibreen (2010) also noticed that forms of greeting vary extensively, and that we have different forms of greeting for each type or status of person. This is the point where we agree with them. In addition, we will try to reveal such correlations between the Persian and English speech communities according to different genders, generations and social status.

A large-scale research work about greetings was carried out by Kirvonos and Knapp (1975) to find out the most recurrent verbal and non-verbal behavior linked with them, and to discover how verbal and non-verbal behavior alter according to the relationships between interlocutors. Accordingly, 64 young men were chosen in order to conduct the analysis and all greeting forms gathered were transcribed. The result of the research stressed the fact that verbal greeting forms were less frequent between strangers. They classified greetings into verbal-nonverbal forms.

Halliday (1973) proposed his own variant of classifying greeting forms according to their relation with time (period of the day when speaker greeted the listener). He called them time-free greeting forms and time-bound greeting forms. Theoretically and practically we will use the above classifications in order to divide the Persian and English analyses of greeting forms into these classes and we will continue their work by arranging verbal greeting forms into subclasses.

Recent studies in the speech act of greeting considered the sociolinguistics of greeting forms. For example, Dezhara and Rezaei (2012) compared greeting forms used by native Persian speakers, on the basis of gender. They came to the conclusion that male and female differences in terms of the linguistic forms used in different situations reveal the fact that men prefer using more informal expressions and feel greater power in comparison to female speakers. By using their work as a background, we will do our best to embrace different types of speech communities in Persian and English.

Akindele (2007) conducted socio-pragmatic analysis of Sesotho greeting forms. He investigated sociolinguistic aspects of greeting in the Basotho's sociolinguistic community. He proposed several types of classification of Sesotho greeting forms. Akindele's work in this field is an important one. However, he focused his attention only on one speech community while our work is going to provide contrastive analysis of sociolinguistic aspects of the 
speech act of greeting in two very different speech communities. We need such research works to be done because they will facilitate difficulties that may appear in interpersonal communication between English and Persian.

Agyekum (2008) describes Akan greetings as the basic oil of social relations that sets the tone and establishes the relationship between the interlocutors. The relationship may show affirmation of equality or enact social inequalities. Thus, greetings can be used to indexicalize the social relationship between and among the interlocutors.

\section{Method}

\subsection{Participants and Instruments}

In order to achieve the goal of such a large-scale research, we divided participants and instruments into several groups according to methods of analysis. The first group consisted of students at Sama High School in Kermanshah. We observed their everyday conversations and paid attention to turn-taking and gender difference. We asked them to fill questionnaires according to their preferences for exact greeting forms. Also, we observed them in a process of statistical analysis. The second group consisted of elder teachers of the same School who were involved in the same processes as their students. Students and teachers with other participants were grouped according to young and elder generations. The third group consisted of a group of instruments. There were approximately 50 videos and audio tapes that we observed. The participants provided a great deal of information concerning the speech act of greeting by referring to their personal practice and internalization of the customs of greeting.

\subsection{Procedure}

In the present article, we tried to define the influence of gender, generation and some social status on the greeting forms of the Persian and English speech communities. This made our research work a large-scale one. Therefore, we used methods from both Qualitative and Quantitative research methods. They were the above-mentioned questionnaires, observation of discourse, descriptive analysis and inferentially statistical analysis.

First, we spent some time on the process of observing how frequently both male and female members of the Persian speech community used different forms of greeting in order to reveal which gender preferred what greeting form and also why some women used non-verbal greeting forms when they met elder ones. We examined these processes by employing descriptive and inferentially statistical analysis. In addition, we used many questionnaires to determine which gender prefers which greeting forms.

We conducted an observation of conversation between the members of one generation, and between men and women's single-sex conversation. Then in order to find out the sequence of turn-taking in discourse, we examined conversation between different generations, and different sexes.

When it came to the same aspects of English speech community, we analyzed a number of video and audio materials with descriptive and inferentially statistical analysis, and moreover observed the conversations.

\section{Results}

The capability of people for expressing greetings based on gender diversities, social status, and educational background of the speaker were interesting to elaborate. We chose both Persian and English as the object of this study because these speech communities have very different cultures and ways of performing conversation. 


\subsection{The Speech Act of Greeting and Greeting Forms in Persian}

Greetings are particularly important for the Persian people. We have many proverbs about the importance, the role and the traditions of greeting. We say, "Well-mannered person greets from a distance" and "to greet is a duty". Greeting is the specific part of the Persian's hospitality, tradition and culture.

Persian has a rich stock of both verbal and non-verbal greeting forms. According to the time orientation, verbal Persian greeting forms can be classified into two basic sub-categories: time-free and time-bound. In this paper, we have tried to divide all Persian greeting forms into these two sub-categories. Our classification of Persian greeting forms is mentioned below:

\subsubsection{Time-Free Persian Greetings}

a. chetori? ${ }^{1}$ With its variants "halet chetore?"2 [How do you do?]

b. salam. ${ }^{3}[\mathrm{Hello} / \mathrm{Hi}]$

c. halet khube? ${ }^{4}$ [How do you do?]

d. oza' bekame? ? $^{5}$ [Everything's ok?]

e. salamat bashi! ${ }^{6}$ [Hope you are in a good health]

f. khosh bashi! [Have fun]

g. salamu alaykum! ${ }^{8}$

h. alaykum as-salam! ${ }^{9}$

\subsubsection{Time-Bound Persian Greetings}

Daily formal greetings:
a. sobh bekheir $!^{10}$ [Good morning]
b. ruz bekheir! ${ }^{11}$ [Good day]
c. asr bekheir! ${ }^{12}$ [Good evening]
d. shab bekheir! ${ }^{13}$ [Good night]

As in English, all daily formal Persian greetings express good wishes for a specific time of the day (Grzega, 2008).

Seasonal (in) formal greetings:
a. tavallodet mobarak! ${ }^{14}$ [Happy birthday to you]
b. sale no mobarak! $!^{15}$ [Happy New Year]

\footnotetext{
${ }^{1} / \mathrm{t}$ êto'..i/

$2 /$ ha' let $^{\text {h }}$ t $\int \hat{e t o '}^{\prime}$ 'e/

3 /sa'lam/

4 /ha'leth $\hat{\text { x̂u be/ }}$

5 /Ro'za? beh 'k 'ame/

${ }^{6} /$ sala' mat $^{\text {th }}$ ba' $\int: \mathrm{i} /$

7 /रिof ba' $: \mathrm{i} /$

8 /salamon?alaj 'k ${ }^{\mathrm{h}} \mathrm{om} /$

9 /Palejkomas̄s̄a' lam/

10 /ŝob̆hbe' xej.i//

11 /.̂uzbe' xej.̊̀/

12 /' ?̧as:.sbe'xej.I/

13 /Jabbbe' xej.̊/

$14 / \mathrm{th}^{\text {haval' }}$ lodet moba'.rac/

15 /sal 'no moba'.ıac/
} 
The most informal verbal Persian greeting forms were used in conversation between younger generations, friends, close relatives and interlocutors who had equal social status.
a. salam. [Hi]
b. halet chetore? [How are you?]
c. halet khube? [How do you do?]
d. khubi? ${ }^{1}$ [Abbreviated form of 'How are you?']
e. chetori? [How do you do?]

These forms of greeting were usually employed in the face-to-face conversation. It appears that nowadays younger generations pay particular attention to non-verbal greeting forms. They interlink verbal and non-verbal greeting forms to show their attitude toward the interlocutor. For example, young people who had just got acquainted might only interlink verbal greeting with hand shaking. Nevertheless, if close friends were males, they could hug each other. If they were females, they could kiss each other on the face. We observed the tendency of using a gesture of 'friendship' as a non- verbal greeting among the younger generations. They use this gesture as means of showing that everything is fine, which is the answer to the question form of greeting 'How do you do?' They can just exchange answers to the question that is supposed to be asked in the form of a greeting. Such a tendency is popular among the younger generations of both Persian and English speech communities.

In formal occasions, young people say 'Salam' when they are greeting a person who is from the same generation. Then it can be continued by one of the next questions regarding how the speaker himself is filled ("halet chetore?" [How are you?], "oza'et chetore?", [How do you feel (yourself)?]). In addition, young people tend to use time-bound greeting forms as well as 'Salam' in formal occasions. Mainly it happens when interlocutors present are of the opposite sex. A man is supposed to say his listener's name after a time-bound greeting in such conversational situations in order to maintain the strategy of politeness. This way of greeting between members of the opposite sex is established as a standard social convention.

Two examples of this case are given here when the time-bound greeting is followed by the listener's first/last name:

1) Young male: asr bekheir, Sima! ${ }^{3}$ [Good evening, Aliya!] Young female: asr bekheir! ${ }^{4}$ [Good evening!]

2) Young male: asr bekheir, Samira! $!^{5}$ [Good evening, Gulnara!] Young female: Salam! [Hi!]

In these examples 'Sima' and 'Samira' are personal names, and the use of personal names reveals a close relationship between interlocutors. So we can see that when the representatives of opposite sex meet each other, men seem less informal and women are more polite. Even in formal occasions, young people do not use honorific titles or personal pronouns in Persian, when they are expressing the speech act of greeting. However, the English do use honorific titles in formal meetings.

As for the conversation between interlocutors who represented different generations, young people were generally assumed to respect the elder ones. And elder generations were

\footnotetext{
${ }^{1} / \hat{\mathrm{xu}} \mathbf{\prime}^{\prime} \mathrm{bi} /$

${ }^{2} /$ /Ro'za?̧et t feto' te/

3 /' ?as:sbe' xej.I s:i'ma/

$4 /$ '? as: Ibe ' xej.i//

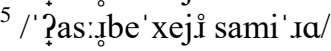


also believed to keep a strategy of politeness. In such cases, the gender does not determine who is supposed to greet first in Persian speech community. It is whoever considers his or her co-participant worthy of greetings. Nevertheless, if the female interlocutor is an elder woman and the male participant is younger than her, it is the male who is supposed to greet first because of the woman's age, and vice versa. In other words, in a normal Persian speech society, a younger person is expected to initiate the greeting. But the context can also produce a variable that defines who should greet first. For example, if a participant enters into a group of people, in that case he has to greet the group first. Further analysis of the results revealed that younger people use variations of the greeting forms.

All above-mentioned variations of greeting forms were polite greeting forms. First, three greeting forms are used when a young person greets an elder man or woman. A young person can also greet an old man with fewer words. As an answer to this kind of greeting, the old man may reply with a speech act wishing him or her 'a longer life.' We did not notice such a thing in the English speech community. The elder English man does not express a speech act of wish when a younger man greets him because such respect and politeness is not valued in English speech community. For example:

1. Young person: haletun khube, pedar jan! ${ }^{1}$ [Dad, how do you do? pedar is a polite Persian word which means an old man]

Old man: khoda omret bede, azizam! khubam! ${ }^{2}$ [Live a long life, my dear! I am all right!]

2. Young person: haletun khube, pedar jan! $!^{3}$ [Dad, how do you do?]

Old man: shad bashi, azizam! ${ }^{4}$ [Have fun, my dear!]

3. Young person: salamatin $?^{5}$ [Hope you are in good spirits]

Old man: khodaro shokr! khubam, azizam! ${ }^{6}$ [Thanks to God! I'm fine, my dear!]

4. Young person: salam alaykum!

Old man: alaykum as-salam!

Mainly when a young woman greets the elderly, they speak in a low level of a voice, and in some cases the woman can bend her head as a non-verbal greeting. Young people ought to be able to greet elder ones and ask not only about their welfare, but also about the welfare of their relatives. This is one of the peculiarities of Persian speech act of greeting. The phenomena that attracts for the length of the greetings is time. People who are not in rush may use engaging greetings when they have free time. For instance:

1. Young person: salam alaykum, pedar! Haletun khube? Khanevade chetoran? ${ }^{7}$ [Hello, dad! How do you do? How about your family?]

Old man: āli! Khodaro shokr! To chetori? ${ }^{8}$ [Everything is ok! Thanks to God! What about you?]

\footnotetext{
$1 /$ ha' lat ${ }^{\text {h}}$ un 'xube phe' da.i ' d $\int \mathrm{on} /$

$2 /$ x̂' da '? '?omiet be' de ?a'zizam 'xubam/

${ }^{3} /$ ha' lat $^{\text {h }}$ un 'xube phe' da.i 'd $\int^{\circ} a n /$

${ }^{4} / \mathrm{Jad}$ 'ba $\mathrm{ji}$ ' $\mathrm{xa}$ 'zizam/

$5 /$ salama' thin/ $^{\text {hin }}$

${ }^{6} /$ x̂o' da.̊ㅇ ' 'Tokı ' $x$ ůbam Pa'zizam/

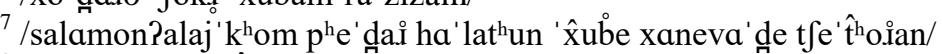

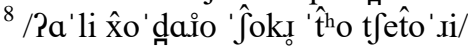


2. Young person: haletun khube? Khanevade chetoran? ${ }^{1}$ [How do you do? How is your family doing?]

Old man: zende bashi! Khodaro shokr hame khuban! ${ }^{2}$ [Live a long life! Thanks to God, everyone is good!]

That was all the information revealed during our research work about the speech act of greeting, communicative competence and its functions according to the speech act of greeting in Persian. For Persian people not replying to a greeting is worse than being an impolite person; it is seen as a sign of arrogance and animosity.

\subsection{The Speech Act of Greeting and Greeting Forms in English}

As the Persian people, the English people also have their own ways and traditions of greeting and expressing the speech act of greeting. A lot of scholars have done their research on the theme of the English speech act of greeting. One of these studies was done by Grzega (2008). He examined the English speech act of greeting from the perspective of etymology and proposed a chronological development of greeting forms. But nowadays there are many people in Britain and in United States who come from various origins with regional and temperamental differences. It is especially difficult to make generalizations about American manners and traditions. The same is true about the ways of expressing speech acts. In the next section, we will attempt to show a few characteristics of the greeting that are common enough to be employed in making generalization. In a time-free and time-bound categorization, English greeting forms may be divided into two main groups:

\subsubsection{Time-Free English Greetings}
a. Hello!
b. Hey!
c. What's up?
d. How do you do?
e. How are you?
f. Nice to see you!

\subsubsection{Time-Bound English Greetings}

Daily formal greetings
a. Good morning!
b. Good evening!
c. Good day!
d. Good night!

Seasonal formal/informal greetings
a. Happy New Year!
b. Happy Anniversary!
c. Happy birthday!
d. Merry Christmas!

In informal occasions both British and American people can just say "Hi" and smile at each other. But in some formal occasions they shake hands. And women shake hands less frequently than men. But handshakes are not verbal; therefore they do not represent the

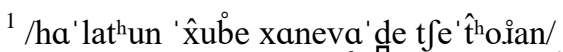

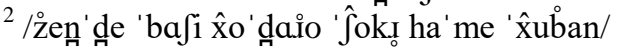


speech act. Nowadays the young generations in America tend to use greeting forms like "What's up?" and "Hi!". The greeting speech act "What's up?" equates to "How are you?" (Vyas \& Patel, 2009).

Greetings such as "Hi" and "Hey" may be followed by the person's name. The greeting form "Hello" is becoming old-fashioned as it is rarely used nowadays. You can hear it mainly at the beginning of the telephone conversation.

In addition, the younger generations do not pay attention to honorific titles when they greet each other on informal occasions. However, when they greet elder persons they do not omit those titles from greetings. In such cases they mainly use time-bound greeting forms and some polite greeting forms. We can refer to the list of polite greeting forms like "How do you do?", "Glad to meet you!", and "Nice to see you!". The sex variable does not have any important and noticeable influence on the speech act of greeting in English. The English like to making compliments before or after greeting. For example:

Max: Yeah! Oh man, you look fantastic. You haven't aged a day.

John: Thanks man!

Like Persian people, The English may also ask about the welfare of the interlocutor after greeting or the speech act of greeting.

\section{Discussion}

Regarding the first research question which was asked about the influence of some social variables on speech act of greeting in Persian and English, the results showed that social variable of generation influenced both languages to a similar degree, but social variable of gender influenced the Persian greetings more than those of English.

With regard to the second research question both Persian and English greetings are mainly started by the interlocutor of lower status and responded to by the interlocutor of high status, but in some cases the interlocutors do not share this convention. If in some greeting situations Persian people may express the speech act of wishing, in some cases the English may express the speech act of compliment. We have found out that Persian people put more importance on the process of greeting the elderly than the English and American people. In addition, the sex variable in Persian greeting is more noticeable than in English.

With regard to the third research question of this study, a pure contrastive analysis of the Persian and English speech act of greeting showed that there exist certain sociolinguistic peculiarities and similarities, which can be helpful as a learning material for Persian students to build their communicative competence for the English speech act of greeting.

\section{Conclusion}

As a speech act, greeting is really of high importance. Moreover, knowledge about time, place, and ways of greeting your interlocutors with different social background is worth learning by heart.

The results of the present study may be used as additional information about communicative competence while teaching Persian students about the speech act of greeting in the English. Knowledge about the differences in sociolinguistic aspects of speech acts forms a useful background for developing communicative competence in the target language. This knowledge can help to overcome misunderstandings which may occur at the beginning of the intercultural conversation. 


\section{References}

[1] Li, W. (2010). The functions and use of greetings. Canadian Social Science, 6(4), 5662.

[2] Tagliamonte, S. A. (2006). Analysing Sociolinguistic Variation. Cambridge: Cambridge University Press.

[3] Austin, J. L. (1962). How to Do Things with Words. Oxford: Oxford University Press.

[4] Searle, J. R. (1969). Speech Acts. Cambridge: Cambridge University Press.

[5] Nemani, F., \& Rasekh, A. E. (2013). Investigating the Effect of Social Variables on Speech Variation: Social Class, Solidarity, and Power. British Journal of Education, Society \& Behavioural Science, 3(3), 300-334.

[6] Jibreen, M.K. (2010). The Speech Act of Greeting a Theoretical Reading. Journal of Kerbala University, 8(1), 1-25.

[7] Goffman, E. (1971). Relations in Public. New York: Basic Books.

[8] Firth, S. (1973). Greetings from the Highlands of Yemen. American Ethnologist, 13 (2), 290-308.

[9] Duranti, A. (1997). Universal and Culture-Specific Properties of Greeting. Journal of Linguistic Anthropology, 7(1), 63-97.

[10] Kirvonos, P. \& Knap, M. (1975). Initiating Communication: What Do You Say, When You Say Hello? Journal of Central State Speech, 26, 115-125.

[11] Halliday, M.A.K. (1973). Explorations in the Functions of Language: Exploration in Language Studies. London: Edward Arnold.

[12] Dezhara S., Rezaei O., Davoudi S., Kafrani.R.S. (2012) A Comparative Study of Greeting Forms Common among Native Male and Female Speakers of Persian. Journal of Language Teaching and Research, 3(6), 1224-1232.

[13] Akindele D.F. (2007). Lumela/Lumela: A Socio-Pragmatic Analysis of Sesotho Greetings. Nordic Journal of African Studies, 16(1), 1-17.

[14] Agyekum, K. (2008). The Pragmatics of Akan Greetings. Discourse Studies, 10(4), 489-512.

[15] Grzega, J. (2008). "Hłl, Hail, Hello, Hi: Greetings in English Language History". In A. H. Jucker, \& I. Taavitsainen (Eds.), Speech Acts in the History of English (pp. 165193). Amsterdam/Philadelphia: John Benjamins.

[16] Vyas, M. A. \& Patel, Y. L. (2009). Teaching English as a Second Language: A New Pedagogy for a New Century. New Delhi: PHI Learning Private Limited. 